\title{
KINERJA DINAS PERINDUSTRIAN DAN PERDAGANGAN (DISPERINDAG) DALAM VIDEO INFORMASI UNTUK MEMBERDAYAKAN INDUSTRI KECIL DAN MENENGAH DI KABUPATEN TANGERANG
}

\author{
Ari Eviawan ${ }^{l}$ \\ Falday Kurniawan ${ }^{2}$ \\ Akhirul Agustian ${ }^{3}$ \\ STMIK Raharja Jurusan Teknik Informatika ${ }^{1,2,3}$ \\ Jl. Jendral Sudirman No. 40, Modern Cikokol, Tangerang ${ }^{1,2,3}$ \\ Email : ari.eviawan@raharja.info ${ }^{1)}$, falday@raharja.info ${ }^{2)}$, akhirulagustian@raharja.info ${ }^{3)}$
}

\begin{abstract}
ABSTRAK
Saat ini keterbukaan akses informasi memungkinkan informasi dapat dengan mudah diperoleh kapanpun dan dimanapun. Informasi menjadi hal penting, karena dengan informasi orang akan mendapat semua yang diinginkan. Penyebaran informasi tersebar melalui media cetak atupun media elektronik berbentuk multimedia, dari media itulah masyarakat dapat memperoleh informasi. Dinas Perindustrian Dan Perdagangan (Disperindag) adalah salah satu instansi pemerintah bidang Perindustrian dan perdagangan, Dinas Perindustrian Dan Perdagangan (Disperindag) yang terbilang baru dan masih mnggunakan media lisan dan tulisan, pameran pendidikan dan website namun media tersebut kurang efektif untuk menginformasikan dan memperkenalkan Dinas Perindustrian Dan Perdagangan (Disperindag), maka pihak Dinas Perindustrian Dan Perdagangan (Disperindag) membutuhkan media video informasi untuk menunjang berbagai kegiatan seperti menginformasikan kepada masyarakat luas khususnya untuk usaha menegah yang berniat untuk menunjukan usaha menengah atau home industry. Pada konsep tersebut terdapat tahapan preproduction, production dan postproduction. Agar menghasilkan rancangan media berbasis video informasi yang baik dan berkualitas digunakan aplikasi penunjang adobe photoshop CS3, Adobe Premier CS3 dan afterb effek CS3.
\end{abstract}

Kata Kunci : media, video, informasi.

\begin{abstract}
The current openness allows access to information information can be easily retrieved whenever and wherever. The information is important, because with information people will get all it wants. Dissemination of information is spread through the media print shaped electronic media atupun multimedia, from the media that the public can obtain information. Department of industry and trade (Disperindag) is one of the Government agencies fields of industry and commerce, Service industry and trade (Disperindag) which is new and still use the spoken and written media, education and exhibition website but the less effective media to inform and introduce the Department of industry and trade (Disperindag), the Department of industry and trade (Disperindag) in need of video media information to support a variety of activities such as informing the public at large to medium size businesses that intend to show the efforts of medium or home industry. On the concept of there stages of preproduction, production and postproduction. In order for video-based media design producing good information and good quality used applications supporting adobe photoshop CS3, Adobe Premiere CS3 and afterb effek CS3.
\end{abstract}

Keywords: media, video, information. 


\section{PENDAHULUAN}

Beragamnya bentuk media informasi merupakan pengaruh dari perkembangan teknologi informasi, dari bentuk media informasi yang digunakan akan menentukan tingkat keberhasilan dalam melalui komunikasi. Sektor Pariwisata merupakan merupakan salah satu bagian kegiatan yang dapat membantu pertumbuhan perekonomian suatu negara, seperti Indonesia misalnnya. Indonesia adalah salah satu negara yang mengandalkan sektor Pariwisata sebagai pemasukan devisi negara, hal tersebut didasarkan kepada kondisi alam, potensi alam yang dimiliki, luas wilayah serta budi - daya, budi daya yang dilakukan oleh masyarakat yang mempunyai daya - tarik terhadap turis turis atau pengunjung yang berkunjung ke Indonesia. Secara culture Indonesia banyak memiliki kegiatan - kegiatan yang kuantitas dan kualitasnya tidak dimiliki oleh bangsa lain. Memiliki banyak daya tarik, hal tersebut bisa ditunjukan ragam budaya dari sabang sampai meraoke. Kegiatan - kegiatan secara kualitas dan kuantitas tidak dimiliki oleh bangsa lain.

\section{RUMUSAN MASALAH}

Berdasarkan hasil wawancara pada Dinas Perindustrian dan Perdagangan Kabupaten Tangerang, Promosi yang ada pada saat ini masih menggunakan desain promosi. Desain di sini diartikan bahwa yang ada pada saat ini hanya berupa desain spanduk, bilboard, $\mathrm{x}$ benner dll. Dinas Perindustrian dan Perdagangan Kabupaten Tangerang masih menggunakan desain untuk memastikan masyarakat lebih mengenal. Dapat diambil satu masalah yang mempengaruhi tersebut diantaranya akan kurangnya informasi dan promosi Dinas Perindustrian dan Perdagangan Kabupaten Tangerang.

\section{LANDASAN TEORI Pengertian Informasi}

Informasi adalah data yang diolah menjadi bentuk yang lebih berguna dan lebih berarti bagi penerimanya. Data kenyataan yang menggambarkan suatu kejadian - kejadian dan kesatuan nyata. Kejadian - kejadian (event) adalah kejadian yang terjadi pada saat tertentu.

\section{Pengertian Promosi}

Promosi adalah komunikasi non individu dengan sejumlah biaya, melalui berbagai media yang dilakukan oleh perusahaan, lembaga-lembaga non laba dan individu-individu. Dalam memasarkan produknya perusahaan perlu merangsang dan menyebarkan informasi tentang kehadiran, ketersediaan, ciri-ciri, kondisi produk, dan manfaat atau kegunaan dari produk yang dihasilkan. Kegiatan ini disebut sebagai promosi.

\section{Pengertian Media}

Media adalah sebagai wadah dari pesan yang oleh sumber atau penyalurnya ingin diteruskan kepada sasaran atau penerima pesan tersebut, materi yang ingin disampaikan adalah pesan pembelajaran, dan tujuan yang ingin dicapai adalah terjadinya proses belajar. 


\section{Pengertian Video}

Video adalah merupakan format berbahan dasar pita magnetik yang digunakan untuk keperluan profesional seperti stasiun televisi maupun keperluan pribadi. Pita magnetik yang terdapat dalam kaset video bisa merekam gambar dan suara dengan baik, sementara film hanya dapat merekam gambar.

\section{Pengertian Audio}

Elemen yang wajib ada pada setiap kali menampilkan video karena jika tidak ada audio nantinya video yang ditampilkan terasa kurang lengkap dan kurang menarik untuk dilihat maka dari itu didalam video tersebut dimasukkan beberapa unsur audio seperti music dan efek suara.

\section{Pengertian Audio Visual}

Audio Visual Adalah suatu peralatan yang dipakai oleh para guru dalam menyampaikan konsep, gagasan dan pengalaman yang ditangkap oleh indera pandang dan pendengaran.

\section{Perencanaan Multimedia}

Multimedia adalah kombinasi teks, seni, suara gambar, animasi, dan video yang disampaikan dengan komputer atau dimanipulasi secara digital dan dapat disampaikan dan/atau dikontrol secara interaktif.

\section{Tujuan Multimedia}

Perancangan media Video Feature dengan tampilan visual yang lebih menarik bertujuan agar dapat menunjuang prgram promosi pada Dinas Pariwisata Kabupaten Pati, melalui bentuk media ini diharapkan dapat daya tarik kepada masyarakat yang nantinya diharapkan masyarakat tertarik untuk mengunjungi tempat - tempat wisata yang ada di wilayah Kabupaten Pati.

\section{Tahapan Produksi Audio Visual}

\section{Pra Produksi}

Dalam tahap ini pemain dan crew bekerjasama untuk memproduksi gambar sesuai dengan konsep Naskah yang dipandu dengan Storyboard pada saat pengambilan gambar atau shooting harus berpedoman atau mengacu pada Time Schedule yang telah dibuat. 


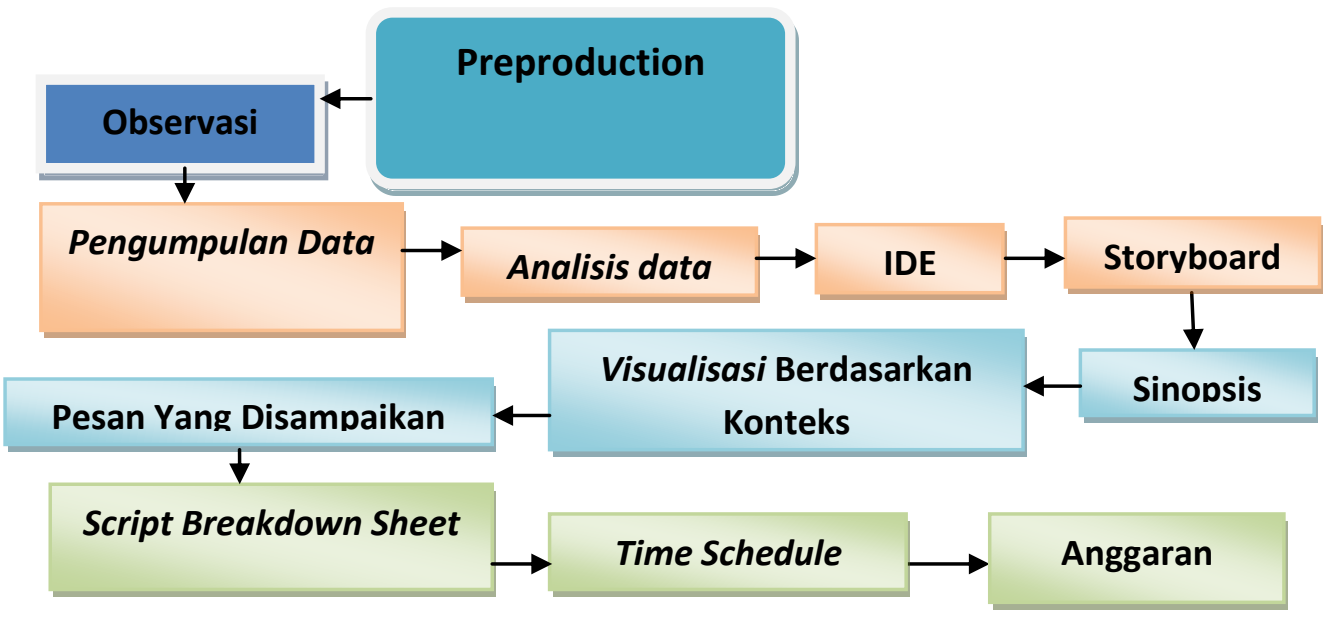

Gambar 1. Tahapan Pra Produksi

\section{Produksi}

Didalam proses Postproduksi inilah perancangan video feature dibuat studi model virtualnya dalam komputer menggunakan aplikasi-aplikasi yang merupakan hasil dari kemajuan teknologi CGI yang biasa digunakan untuk pembuatan film-film Box Office Hollywood. Karakter, properti dan latar belakang yang sudah tertata dalam model virtual yang telah diberi tekstur dan warna yang diinginkan.

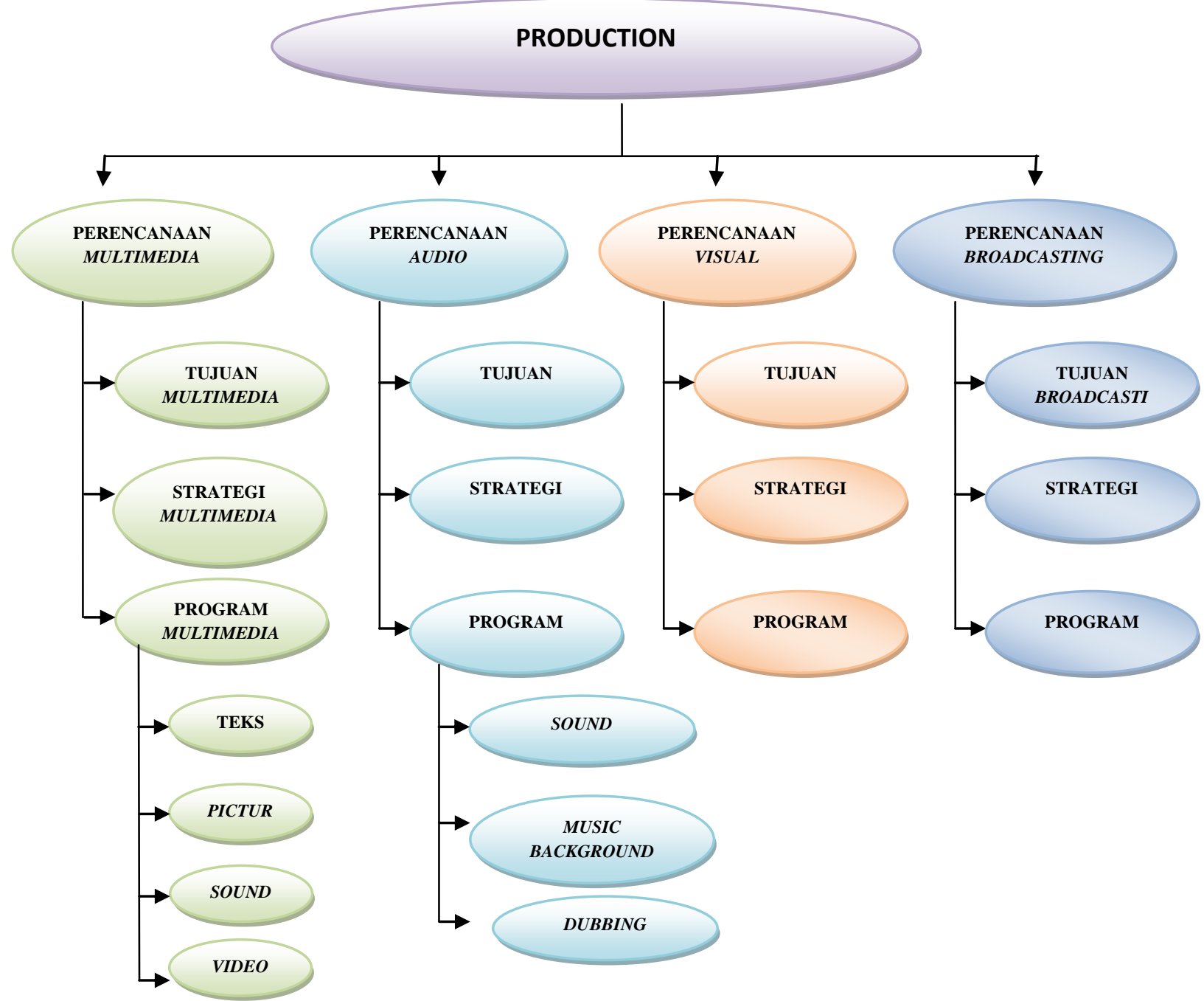




\section{Pasca Produksi}

Gambar 2. Tahapan Produksi

"Pascaproduksi (penyuntingan) adalah semua kegiatan setelah peliputan/shooting/taping sampai materi itu dinyatakan selesai dan siap disiarkan atau diputar kembali."

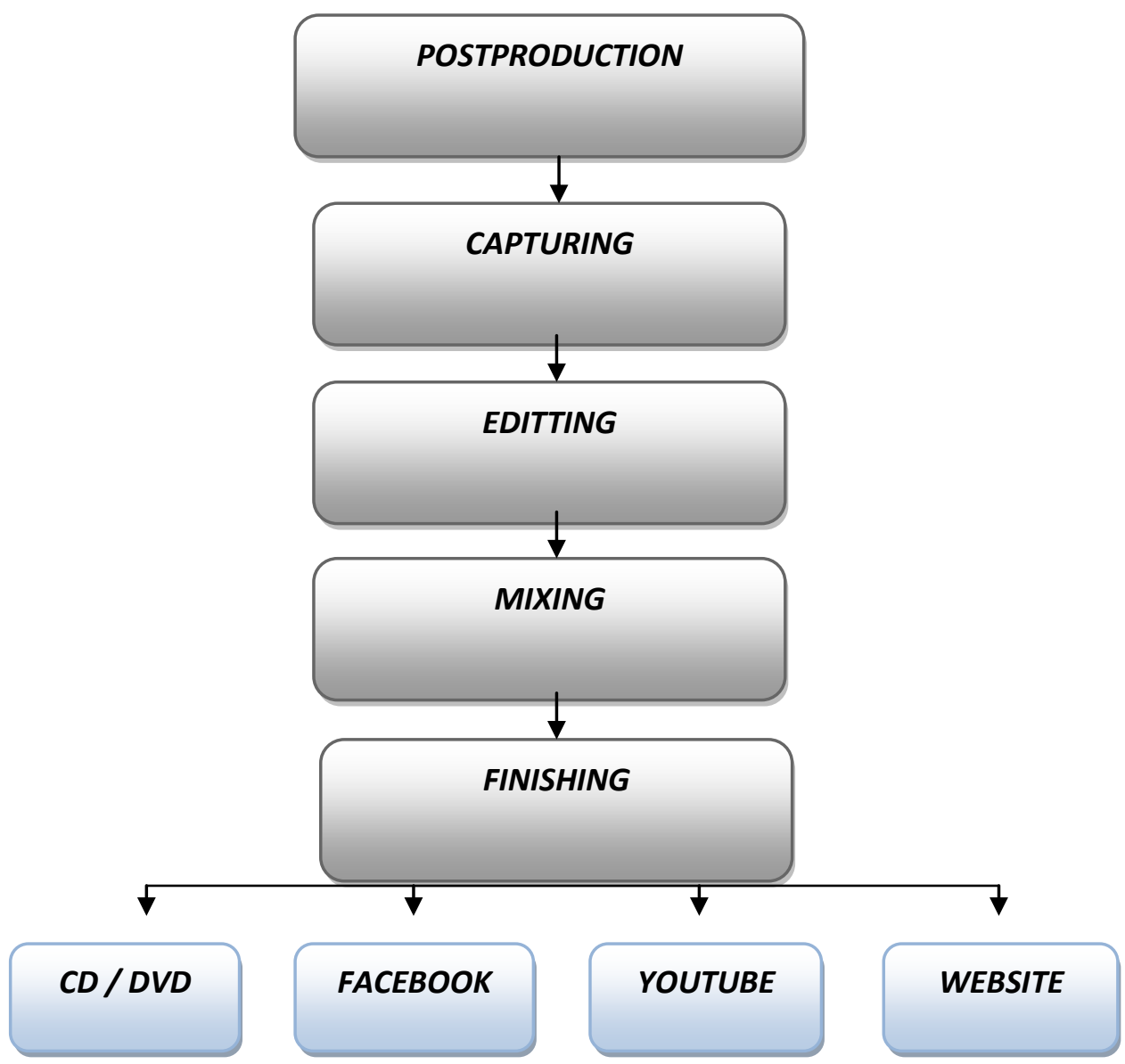

Gambar 3. Pasca Produksi

\section{Storyboard}

Scene 1

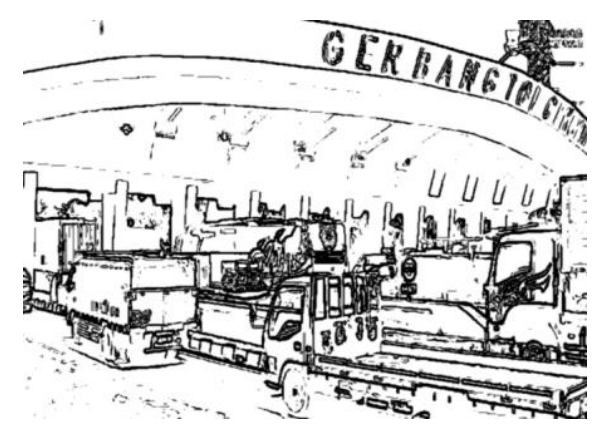

Gambar 4. Gerbang Tol Kabupaten Tangerang

EXT/Gerbang Tol

Kabupaten Tangerang 


\section{Scene 2}

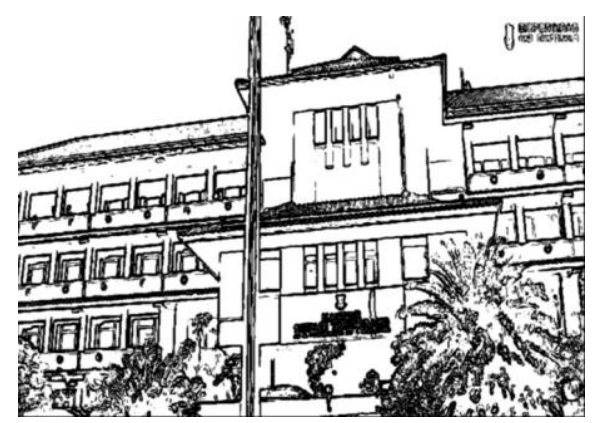

Gambar 5. Pusat Pemerintahan kabupaten tangerang

EXT/ Pusat Pemerintahan kabupaten tangerang (Full Shoot)

Scene 3

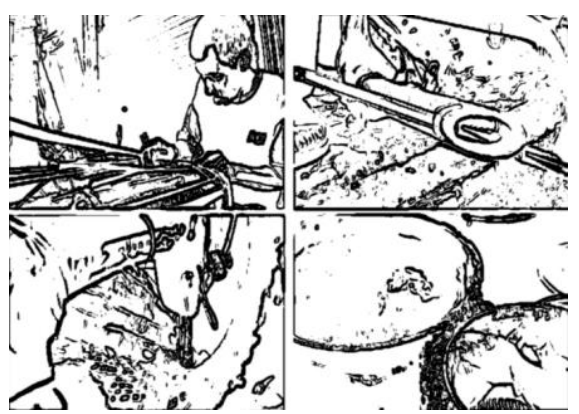

Gambar 6. Slide-slide isi dari projek

Slide-slide isi dari projek

\section{Scene 4}

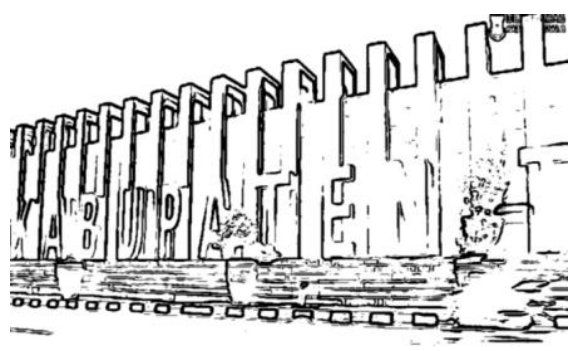

Gambar 7: pintu masuk kabupaten tangerang

EXT / pintu masuk kabupaten tangerang (Full Shoot)

\section{Scane 5}

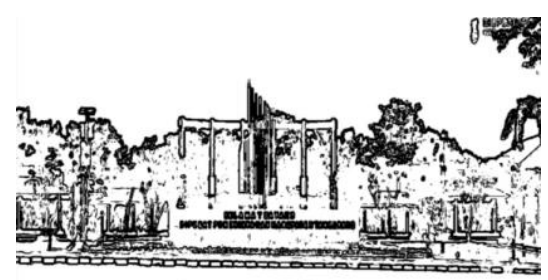

Gambar 8. Depan gerbang pemerintahan kabupaten tangerang 
EXT/ Depan gerbang

pemerintahan kabupaten tangerang

(Full Shoot)

\section{Scane 6}

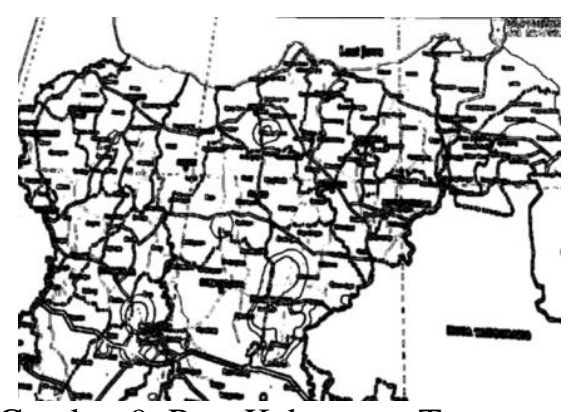

Gambar 9. Peta Kabupaten Tangerang

Peta Kabupaten Tangerang

\section{Scane 7}

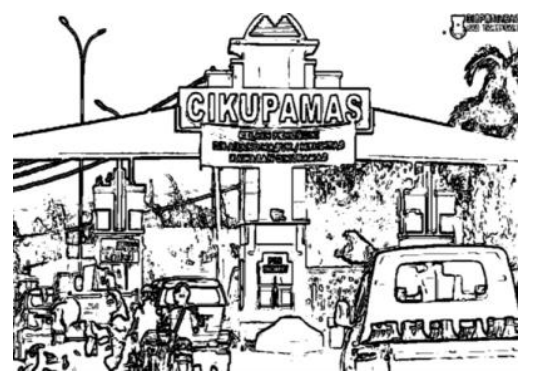

Gambar 10. Wilayah Perindustrian Kabupaten Tangerang

EXT/ Wilayah Perindustrian Kabupaten

Tangerang (Full shoot)

\section{Scane 8}

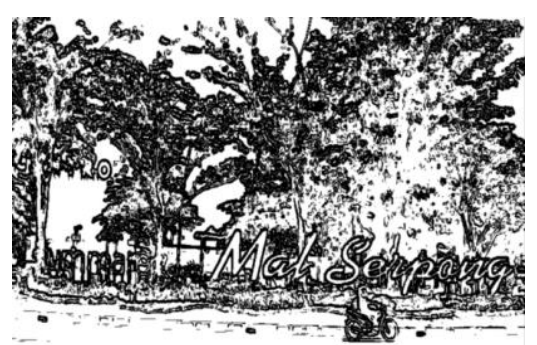

Gambar 11. Wilayah Perdagangan Kabupaten Tangerang

EXT/Wilayah Perdagangan Kabupaten Tangerang (Full shoot) 


\section{Scane 9}

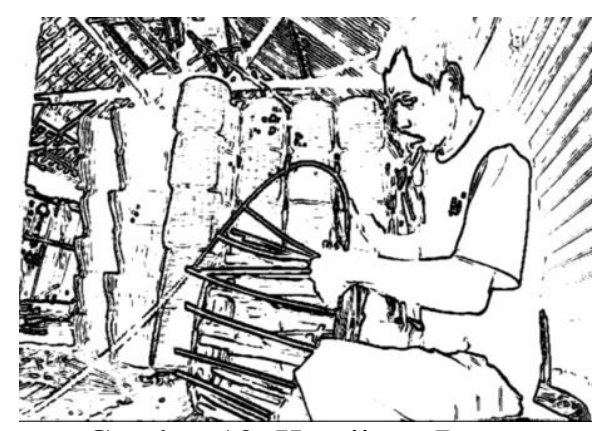

Gambar 12. Kerajinan Rotan

INT/ Kerajinan Rotan (Medium shoot)

Scane 10

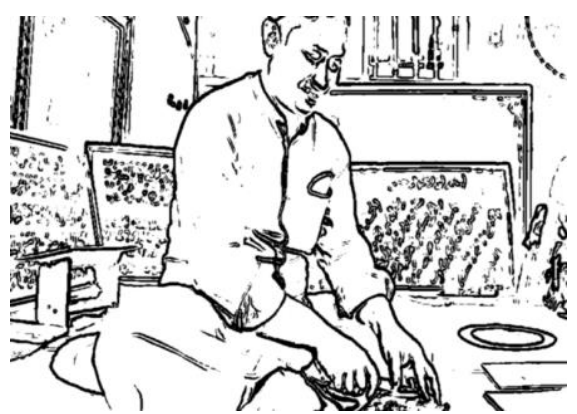

Gambar 13. Ayaman Bambu

INT/Ayaman Bambu (Medium shoot)

Scane 11

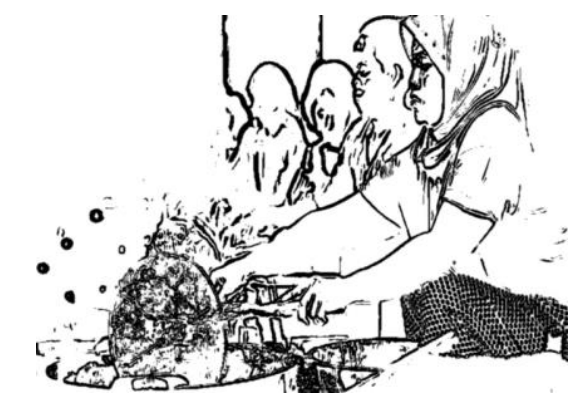

Gambar 14. Makanan dan Minuman

INT/ Makanan dan Minuman (Medium shoot)

\section{Scane 12}

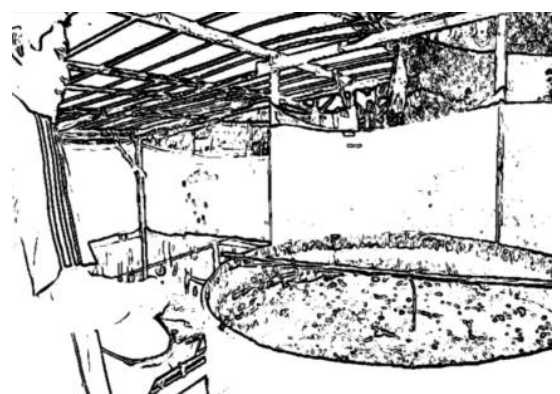

Gambar 15. makanan khas dari ikan 
EXT/makanan khas dari ikan (Medium Full Shoot)

\section{Scane 13}

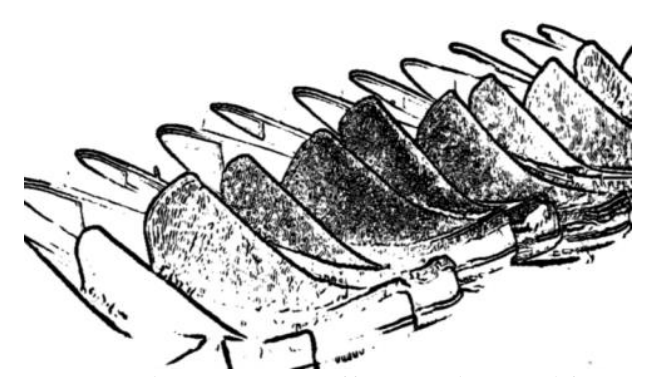

Gambar 16. Kerajinan Alas Kaki

INT/Kerajinan Alas Kaki (Medium Full Shoot)

\section{Scane 14}

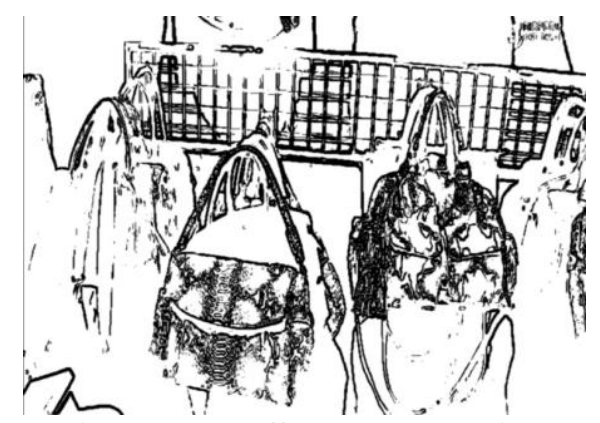

Gambar 17. Kerajinan Dompet dan Tas

INT/Kerajinan Dompet dan Tas (Medium Full Shoot)

\section{Scane 15}

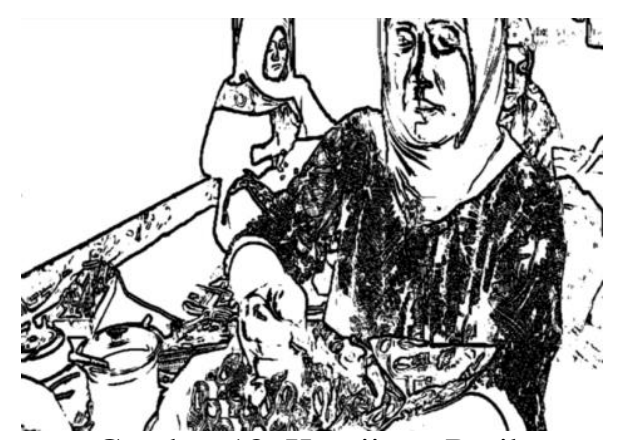

Gambar 18. Kerajinan Batik

INT/Kerajinan Batik (Medium Full Shoot) 


\section{Scane 16}

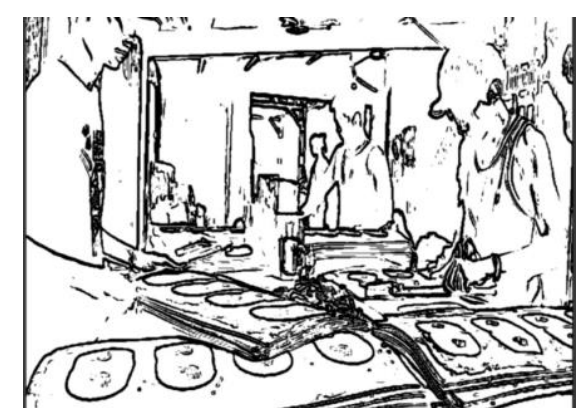

Gambar 19. Konfeksi

INT/Konfeksi (Medium Full Shoot)

Scane 17

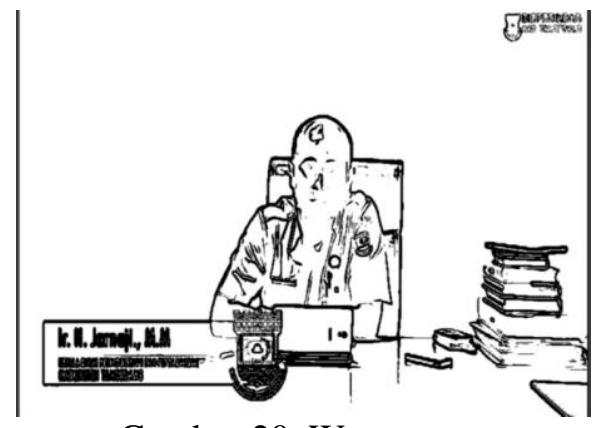

Gambar 20. Wawancara

Wawancara (Medium Full Shoot)

Scane 18

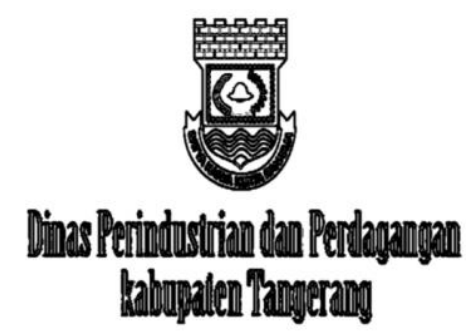

Gambar 21. Closing

Logo dan nama dinas

Adobe Photoshop

Adobe Photoshop adalah software (perangkat lunak) buatan Adobe Systems yang digunakan untuk pengeditan foto/gambar, termasuk pembuatan efek grafis. Adobe Photoshop sering digunakan oleh fotografer digital dan perusahaan iklan (advertising). 


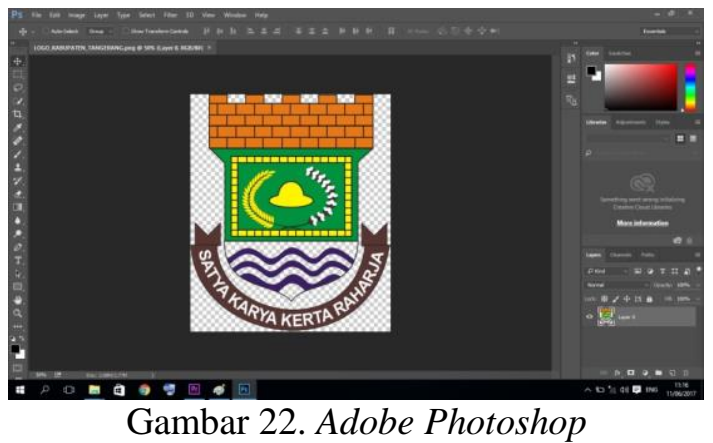

\section{Adobe Premiere Pro}

Program Video Editing yang dikembangkan oleh Adobe. Program ini sudah umum digunakan oleh rumah-rumah produksi, televisi dan praktisi di bidangnya Adobe Premiere Pro merupakan program pengolah video pilihan bagi kalangan profesional, terutama yang suka bereksperimen. Program ini banyak digunakan oleh perusahaan Pembuatan Film/Sinetron, Broadcasting, dan Pertelevisian.

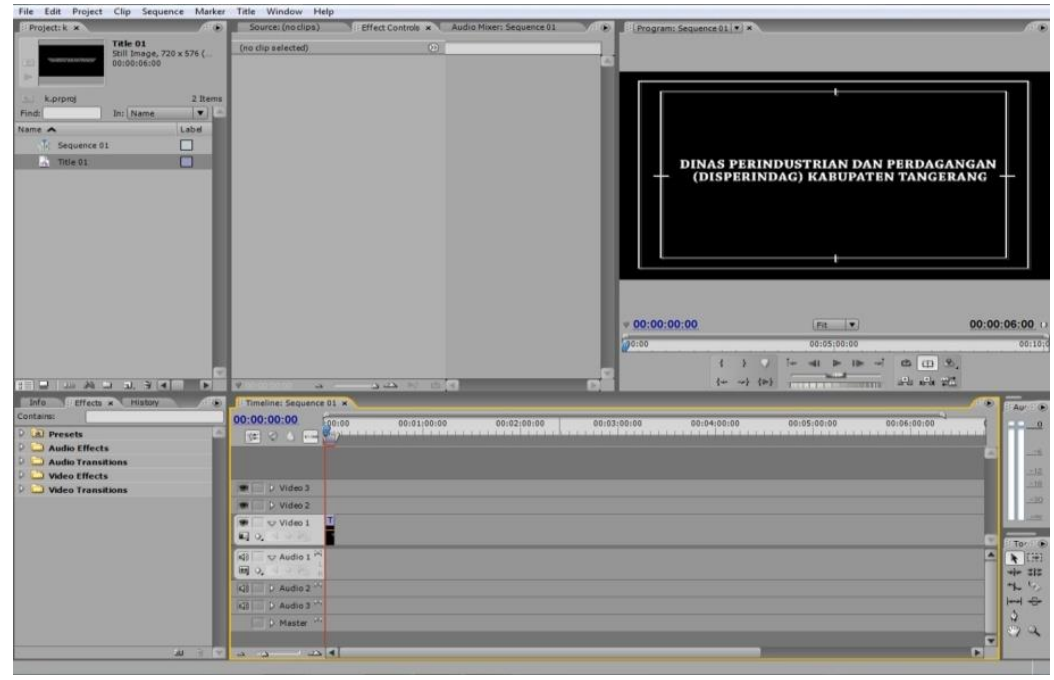

Gambar 23. Adobe Premiere Pro

\section{Literatur Revewer}

1. Penelitian oleh Ramadhan, dkk (2015 : 3) "Citra Pariwisata Kota Bandung Sebagai Kota Art Deco : Studi Kasus Kawasan Asia Afrika dan Braga". Bandung memiliki potensi melalui wisata budaya warisan dalam bentuk bangunan tua pariwisata besar berseni Belanda kolonial arsitektur Art Deco yang banyak di Asia Afrika dan Braga. Art Deco mencirikan identitas atau merek Asia Afrika dan Braga. Perbaikan infrastruktur dan revitalisasi budaya dibawa keluar oleh pemerintah kota Bandung baru - baru ini, penelitian ini adalah untuk mengidentifikasi kondisi merek pengetahuan yang terdiri dari kesadaran merek dan citra merek dari Art Deco di kawasan cagar budaya (warisan budaya) Asia-Afrika dan Barga untuk mengukur bagaimana gambar atau identitas pariwisata Bandung sebagai kota Art Deco sebagaimana dinyatakan dalam rencana induk Pariwisata Nasional 2010 - 2025. Penelitian menggunakan metode kuantitatif, contoh yang digunakan adalah 100 wisatawan yang berkunjung ke Asia Afrika dan Braga dengan distribusi kuesioner online. Selain analisis data juga didukung oleh studi sastra dan observasi langsung di situs studi. Hasil analisis menunjukkan bahwa tingkat kesadaran dari wisata Art Deco pada kategori tengah yang berarti wisatawan tidak 
begitu akrab dengan seni Deco ini adalah karena kurangnya instruksi atau papan informasi tentang Art Deco di sekitar Asia Afrika dan Braga, selain banyak wisatawan sendiri yang tidak tahu ada Art Deco, tapi hasil analisis menunjukkan gambar citra merek dalam kategori baik. Bangunan warisan arsitektur Art Deco terlihat unik dan indah ini memberikan nilai lebih untuk Asia Afrika dan Braga, berdasarkan hal ini dianggap sesuai dengan citra pariwisata di kota Bandung sebagai kota Art Deco.

2. Penelitian oleh Maulani, dkk (2016 : 207 - 220) "Pengembangan Media Promosi Pariwisata Kota Tangerang Dalam Bentuk Video Digital Pada Dinas PORPAREKRAF". Saat ini Dinas PORPAREKRAF, memberikan informasi dan promosi berupa video pariwisata melalui beberapa media yaitu berupa media sosial, maupun website yang dirasa masih belum cukup untuk memenuhi kebutuhan promosi pariwisata yang dirasa kurang uptodate. Dinas PORPAREKRAF harus memiliki sarana media informasi dan promosi yang dapat menunjang kemajuan pariwisata Kota Tangerang.

3. Penelitian oleh Hayati (2014 : 1) "Pemanfaatan Bangunan Bersejarah Sebagai Wisata Warisan Budaya Di Kota Makassar". Zaman kolonial di Indonesia mewariskan sejumlah bangunan sekolah, bank dan kantor. Bangunan yang memiliki nuansa arsitektur Belanda, oleh karena itu menjadi warisan budaya dan atraksi pariwisata. Tujuan dari penelitian ini adalah untuk mengetahui sejarah pemanfaatan bangunan di kota Makassar, Sulawesi Selatan. Namun dalam penelitian ini dipilih tiga bangunan yang dikembangkan sebagai cagar budaya, yaitu Benteng Rotterdam, Museum Kota dan Gedung Kesenian Makassar. Ketiga bangunan bersejarah dipilih sebagai lokasi penelitian karena potensi fisik bangunan arsitektur yang dilengkapi dengan potensi bebas fisik nilai sejarah dan budaya. Penelitian yang diterapkan manajemen objek wisata ini, siklus hidup kawasan pariwisata oleh pelayan pribadi dan pemasaran pariwisata teori untuk mengetahui siklus hidup evolusi setiap bangunan kemudian mengatur strategi yang efektif untuk mengembangkan Fort Rotterdam, Museum Kota dan Gedung Kesenian sebagai cagar budaya di kota Makassar. Artikel berpendapat bahwa pemanfaatan Fort Rotterdam sebagai daya tarik turis diklasifikasikan ke dalam tahap pengembangan. Fort Rotterdam telah beberapa kali direnovasi dengan mengembangkan La Galigo Museum untuk meningkatkan daya tarik. Pemerintah daerah juga memiliki banyak promosi. Museum Kota dan Gedung Kesenian Makassar diklasifikasikan ke dalam tahap eksplorasi sejak dua bangunan bersejarah perlu perbaikan fisik, penataan ruang pamer dan fasilitas menangani koleksi Museum Kota dan jaminan bangunan pengelolaan dan pemeliharaan Gedung Kesenian. Berdasarkan hasil penelitian Fort Rotterdam, Museum Kota dan Gedung Kesenian Makassar tidak hanya memiliki potensi fisik bangunan dan nilai sejarah tetapi juga untuk menjadi daya tarik wisata yang menarik yang perlu ditingkatkan dengan mempertahankan identitas arsitektur sebanyak mungkin, memberikan fasilitas pendukung yang diperlukan oleh wisatawan dan meningkatkan promosi oleh pemerintah daerah.

4. Penelitian yang dilakukan Goenawan, dkk (2013) "Perancangan Video Promosi Pulau Bawean Beserta Media Pendukungnya". Kurangnya perhatian pemerintah terhadap pulau - pulau terpencil di pelosok Indonesia, menyebabkan tidak banyak masyarakat yang tau akan keberadaan serta potensi yang dimiliki dari tiap - tiap pulau tersebut. Pulau Bawean yang merupakan salah satu pulau terpencil yang berada ditengah perairan laut jawa, adalah pulau yang memiliki banyak sekali potensi dibidang 
pariwisata. Keindahan alam yang eksotis, masih alami dan belum banyak dijamah orang, sehingga dibuatlah media yang mempromosikan pulau ini dalam bentuk video promosi, masyarakat menjadi tau akan keberadaan serta potensi dari pulau ini, sehingga dapat berimbas pula terhadap jumlah wisatawan yang akan berkunjung ke pulau yang sedang berkembang ini.

5. Penelitian yang dilakukan Imam, dkk (2017)"Perancangan Media Promosi Video Youtube Koleksi Sanggar Gubug Wayang Mojokerto Berbasis Budaya Sebagai Upaya Meningkatkan Brand Awareness". Tujuan dari desain media promosi Sanggar Gubug Wayang Mojokerto di video youtube berbasis budaya adalah untuk meningkatkan kesadaran merek sebagai sumber informasi agar publik dapat mengetahui dan melestarikan budaya Indonesia. Penelitian ini menggunakan analisis penelitian dengan deskriptif kualitatif yang terdiri dari observasi, wawancara, dan sastra studi untuk mendapatkan data yang digunakan untuk mendukung produksi desain media promosi Sanggar Gubug Wayang Mojokerto di video youtube. Dan dianalisa menggunakan beberapa tahapan, yaitu pengamatan memperpanjang, meningkatkan kegigihan, triangulasi, negatif analisiskasus, penggunaan bahan referensi, dan menggunakan check.

6. Research conducted by Nuansa, dkk (2014 : 82 - 85) "Designing Promotion Strategy of Malang Raya's Tourism Destination Branding Through Audio Visual Media".

This study examines the suitability concept of destination branding with existing models of Malang tourism promotion. This research is qualitative by taking the data directly in the form of existing promotional models of Malang, namely : information portal sites, blogs, social networking, and video via the internet. This study used SWOT analysis to find strengths, weaknesses, opportunities, and threats on existing models of the tourism promotion. The data is analyzed based on destination branding's concept indicators. Results of analysis are used as a basis in designing solutions for Malang tourism promotion through a new integrated tourism advertising model. Through the analysis we found that video is the most suitable media that used to promote Malang tourism in the form of advertisements. Videos are able to show the objectivity of the fact that intact better through audio-visual form, making it easier to associate the viewer thoughts on the phenomenon of destination. Moreover, video creation of Malang tourism as well as conceptualized advertising is still rare. This is an opportunity, because later models of audio-visual advertisements made of this study is expected to be an example for concered parties to conceptualize the next Malang tourism advertising.

(Studi ini meneliti konsep kesesuaian tujuan branding dengan model promosi pariwisata Malang. Penelitian kualitatif dengan mengambil data secara langsung dalam bentuk model promosi Malang, yaitu : situs portal informasi, blog, jaringan sosial, dan video melalui internet. Penelitian ini menggunakan analisis SWOT untuk menemukan kekuatan, kelemahan, peluang dan ancaman di model yang ada pada promosi pariwisata. Data dianalisis berdasarkan konsep indikator tujuan branding. Hasil analisis yang digunakan sebagai dasar dalam merancang solusi untuk promosi pariwisata Malang melalui model iklan pariwisata terpadu baru. Melalui analisis kami menemukan bahwa video adalah media yang paling cocok yang digunakan untuk mempromosikan pariwisata Malang dalam bentuk iklan. Video mampu menunjukkan objektivitas fakta dengan utuh yang lebih baik melalui audio-visual, membuatnya lebih mudah untuk mengaitkan tujuan dari pikiran penampil fenomena. Selain itu, penciptaan video pariwisata Malang dikonseptualisasikan iklan masih jarang. Ini adalah kesempatan, 
karena kemudian model iklan audio-visual dari penelitian ini diharapkan menjadi contoh bagi pihak - pihak yang bersangkutan dengan iklan pariwisata Malang berikutnya).

\section{KESIMPULAN}

Media yang dibutuhkan Disperindag Kabupaten Tangerang dalam menginformasikan dan mempromosikan industry kecil dan menengah yaitu berupa media video informasi, karena menyajikan video yang informatif dan efektif mengenai industri dan usaha menengah Kabupaten Tangerang yang memiliki sejarah panjang dan menyimpan beragam potensi Dalam Memberdayakan Industri Kecil Dan Menengah di Kabupaten Tangerang disertai voice over dengan penyampaian bahasa yang jelas, lugas, dan menarik. Selain itu tampilan visual yang selaras dengan audio dan efek visual yang disajikan, sehingga pesan yang disampaikan mudah dipahami oleh wisatawan.

\section{DAFTAR PUSTAKA}

[1] Abdullah, Ma'ruf. 2015. Metodologi Penelitian Kuantitatif. Yogyakarta : Aswaja Pressindo.

[2] Agustina, Rini dan Ade Chandra. 2017. Analisis Implementasi Game Edukasi "The Hero Diponegoro" Guna Meningkatkan Hasil Belajar Siswa Di Mts. Attaroqie Malang. Jurnal Teknologi Informasi ISSN 2086 - 2989 Vol. 8 No. 1. Jawa Timur : Universitas Kanjuruhan Malang.

[3] Christy, Priscilla. 2015. Pengaruh Desain Kemasan (Packaging) Pada Impulsive Buying. Yogyakarta : Universitas Atma Jaya Yogyakarta.

[4] Daniel. 2015. Pembuatan Video Profil Perguruan Swasta Buddhis Bodhicitta Medan. Medan : STMIK TIME.

[5] Faradiba, Lupita. 2015. Perlindungan Konsumen Melalui Gambar Peringatan Dalam Iklan Rokok Ditinjau Dari Undang-Undang No 32 Tahun 2002 Tentang Penyiaran Dan Undang-Undang No 8 Tahun 1999 Tentang Perlindungan Konsumen. Jawa Timur : Universitas Jember.

[6] Goenawan, Johan Christian. Arief Agung Suwasono. Daniel Kurniawan Salamoon. 2013. Perancangan Video Promosi Pulau Bawean Beserta Media Pendukungnya. Jurnal DKV Adiwarna Vol.1, No.2. Surabaya : Universitas Kristen Petra.

[7] Indratmo, Effy dan Tri Lestyo Handayani. 2014. Studi Manajemen Penyelenggaraan Pameran Seni Rupa Di Bentara Budaya Yogyakarta. Jurnal Brikolase Vol. 6. N0. 1 ISSN : 2087 - 0795. Solo : Institut Seni Indonesia Surakarta.

[8] Yuliana, Ika dan Rony Ika Setiawan. 2015. Pelayanan Dan Promosi Penjualan Terhadap Loyalitas Pelanggan Melalui Keputusan Pembelian (Studi Kasus Pada UD. Kelapa Sari Blitar). Jurnal Riset Mahasiswa Ekonomi (RITMIK) Vol. 2 No. 2 ISSN : 2407 - 2680. Blitar : Sekolah Tinggi Ilmu Ekonomi Kesuma Negara (STIEKEN). 